\title{
Endoscopy and quality assurance - It is here!
}

\author{
David Armstrong MB BChir MA FRCPC FRCP FACG, CAG Endoscopy Committee \\ Roger Hollingworth MD FRCPC, CAG Practice Affairs Committee
}

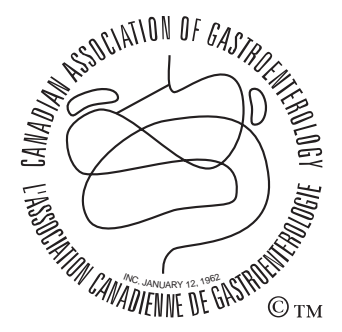

En français voir page 257

$\mathrm{O}$ ver the past year, the Canadian Association of Gastroenterology (CAG) has been exploring ways to measure and address quality aspects of practice. At the 2006 Canadian Digestive Diseases Week, excellent presentations on endoscopy and quality assurance were given by McKenna Memorial Lecturer, Dr Peter Cotton, and in the symposium "Improving Effectiveness and Efficiency of Endoscopy", in which Dr Roland Valori and Dr John Anderson reviewed the many quality-related activities underway in the United Kingdom (UK). In November 2006, the CAG Regional Representation Committee discussed and agreed unanimously that the CAG should champion a quality assurance program in Canada. In response, the CAG Board appointed representatives from the Endoscopy and Practice Affairs Committees to initiate such a program. Quality in endoscopy remained a focus at the 2007 CDDW and the 3rd Annual CASL Winter Meeting, with an evening event being held on this topic.

\section{THE UK NATIONAL PROGRAM ON QUALITY IN ENDOSCOPY}

The national strategy in the UK, implemented over the past two to three years, has encompassed training for endoscopists and endoscopy trainers, and a comprehensive, Web-based endoscopy service evaluation tool - the Global Rating Scale (GRS). The GRS evaluates multiple components of endoscopy service delivery, emphasizing patient-focused aspects including patient satisfaction, successful completion of endoscopy, complication rate monitoring, outcomes and resource utilization as it relates to improving access. The program has been very successful in England, with 98\% of all endoscopy units having completed at least one evaluation using the GRS and the program having completed a fourth cycle of six-monthly evaluations.

A number of factors have contributed to the success of the UK National Health Service (NHS) program:

- The NHS program is supported by central, national funding;

- Most endoscopists working in the NHS are salaried and, therefore, monitoring of endoscopic service quality does not impose a significant financial burden; and

- The NHS has mandated a program to improve delivery of endoscopy services related to bowel cancer screening.
This has thus led to administrative support for the program.

\section{A CANADIAN QUALITY ASSURANCE PROGRAM - IS IT FEASIBLE? WORTHWHILE?}

In Canada, there is no national funding available to develop this program and the CAG does not have the funds to implement the GRS. This is particularly important given that implementation of the GRS by endoscopists is, potentially, time-consuming and financially disadvantageous. Furthermore, there is no direct incentive for nursing staff or for administration to implement the GRS given the other pressures on their time and resources. Yet, the crucial aims of a quality assurance or a quality improvement program provide a compelling argument for overcoming these challenges.

Aims

- To develop a mechanism for continuous quality improvement in the delivery of endoscopy services in Canada;

- To demonstrate that gastroenterologists provide quality care and quality endoscopy with available resources;

- Based on the above, to advocate for additional resources and increased numbers of gastroenterologists;

- To allow gastroenterologists to obtain a 'quality endorsement' for their endoscopy practice or for their endoscopy unit;

- To support communication and liaison among gastroenterologists, endoscopy nursing staff and endoscopy unit managers to improve the overall quality of endoscopy service delivery; and

- To demonstrate that a global assessment of endoscopy services can lead to improvements in specific outcome measures such as patient satisfaction, wait-times and resource utilization.

\section{PILOT PROGRAM ON QUALITY IN ENDOSCOPY}

As an initial step, a quality assurance program based on the UK model (the GRS) will be piloted at a small number of centres (six to eight academic centres and six to eight community-based

The CAG is proud to acknowledge its Benefactor Corporate Sponsors:

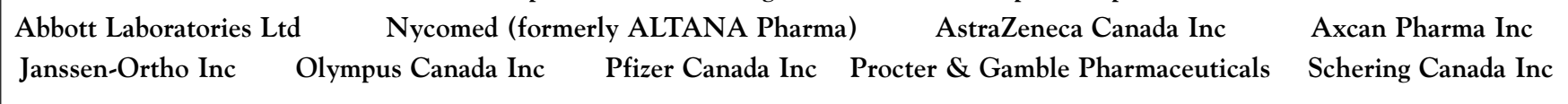


centres) across Canada to evaluate its feasibility. The GRS will also be evaluated in comparison with wait-times and other, more specific, outcome measures; wait times, in particular, can be assessed, as in the 'PAGE' programs, using a short 'point of care' survey, completed on a PDA, such as in the iPaq (Hewlett-Packard Co, Canada) or Palm handhelds (Palm Inc, Canada) or on a smart phone, such as the Blackberry (Research in Motion Ltd, Canada) or Tréo (Palm Inc, Canada). If the pilot program is successful, it will be optimized for the implementation of a broader-scale quality assurance program.

\section{Assumptions}

- The GRS is an appropriate tool for use in Canada. It is already in use in England, with plans for implementation in Scotland, Wales, Northern Ireland and Australia. With minor modifications, including linguistic and contextual changes, the GRS should be used in its current form without further validation or major changes, particularly as there is already a Web site specifically for Canada, and support available for the current version.

- The primary outcome should be focused on wait-time data and specific, locally determined outcomes as an initial step. The overall GRS score (ie, quality assessment of the unit) will be a secondary outcome because this is a complex, multidimensional score that is likely to be an insensitive measure of change resulting from limited interventions.

Pilot centres will:

1. Perform baseline GRS assessments (endoscopist, endoscopy nurse and unit manager);

2. Review GRS data to identify four to six key factors that appear to affect wait-times (eg, backloading, no-shows and inappropriate referrals). These factors may be specific to a centre (local) or they may be relevant to all centres. This step should involve all key stakeholders (ie, nurses and administrators).

3. Perform a short (two-week) survey program to measure current wait-times before any intervention (ie, implementation of steps to address the above identified key factors);

4. Develop one or more specific interventions that target the key factors thought to have the greatest effect on wait-times;
5. Measure outcomes directly related to the intervention(s) (eg, number of cancelled lists and number of 'no-shows');

6. Implement these interventions over a period of three to six months;

7. Repeat the wait-time survey program after the intervention period;

8. Repeat the measure of outcomes directly related to the intervention(s) (eg, number of cancelled lists and number of 'no-shows'); and

9. Repeat GRS assessment.

Timelines

Q1 - Q2/2007 Recruit pilot centres.

Q2/2007 Perform baseline GRS and short wait-time survey.

Q2/2007 Assess data, identify key factors and implement change. Assess baseline measurement of outcome for key factors.

Q4/2007 Repeat GRS and short wait-time survey. Repeat measurement of outcome for key factors.

Successful implementation will require collaboration with other stakeholders. At its most basic level, completion of the GRS requires input from an endoscopist, an endoscopy nurse and an administrator. Changes designed to improve specific aspects of service delivery may initially be implemented on a site-by-site basis. However, as the program develops, regional administrations, patient organizations, provincial governments, and Ministries of Health and affiliate organizations, such as the Canadian Association of Gastrointestinal Surgeons and the Canadian Society of Gastrointestinal Nurses and Associates will become important.

We hope that you support the importance of establishing a quality assurance program. To submit your comments and questions and/or to indicate your interest in participating please contact:

$$
\begin{gathered}
\text { The CAG National Office } \\
2902 \text { South Sheridan Way, Suite 201, } \\
\text { Oakville, Ontario L6J 7L6. } \\
\text { Fax 905-829-0242 or e-mail cagoffice@cag-acg.org }
\end{gathered}
$$

More information on the NHS program and the GRS can be found at: http://www.grs.nhs.uk 


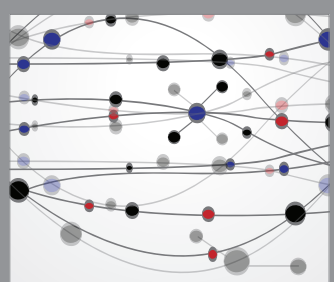

The Scientific World Journal
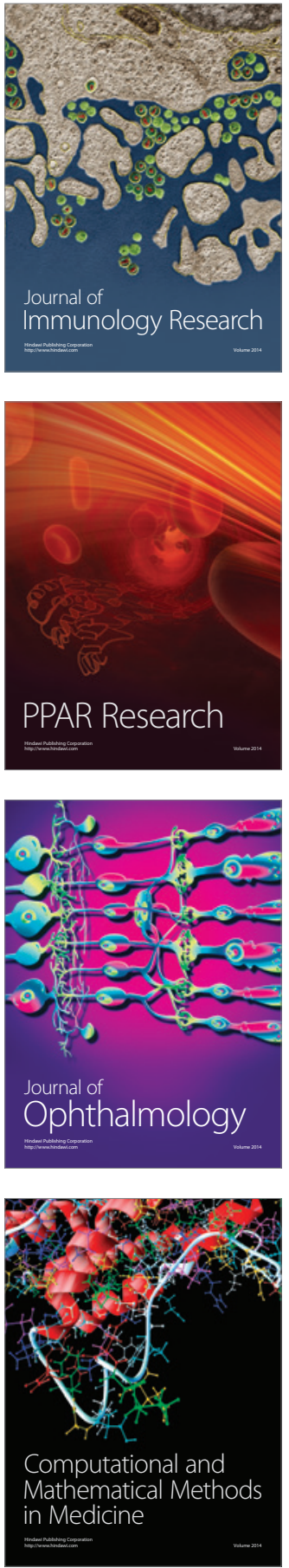

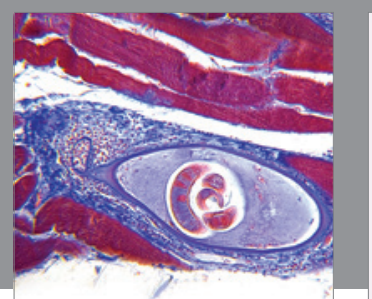

Gastroenterology Research and Practice

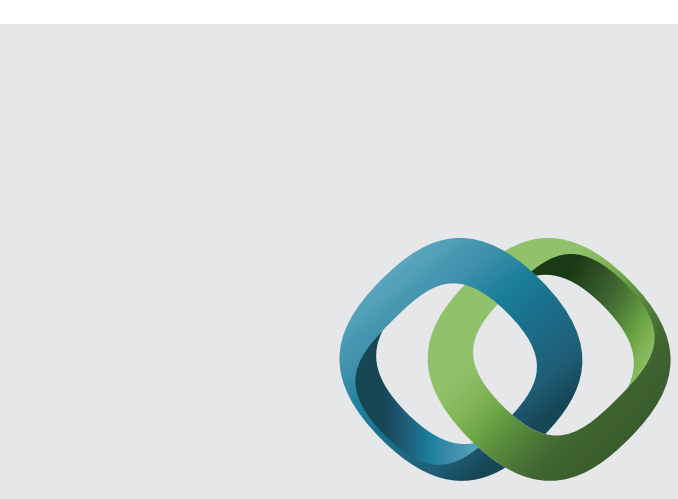

\section{Hindawi}

Submit your manuscripts at

http://www.hindawi.com
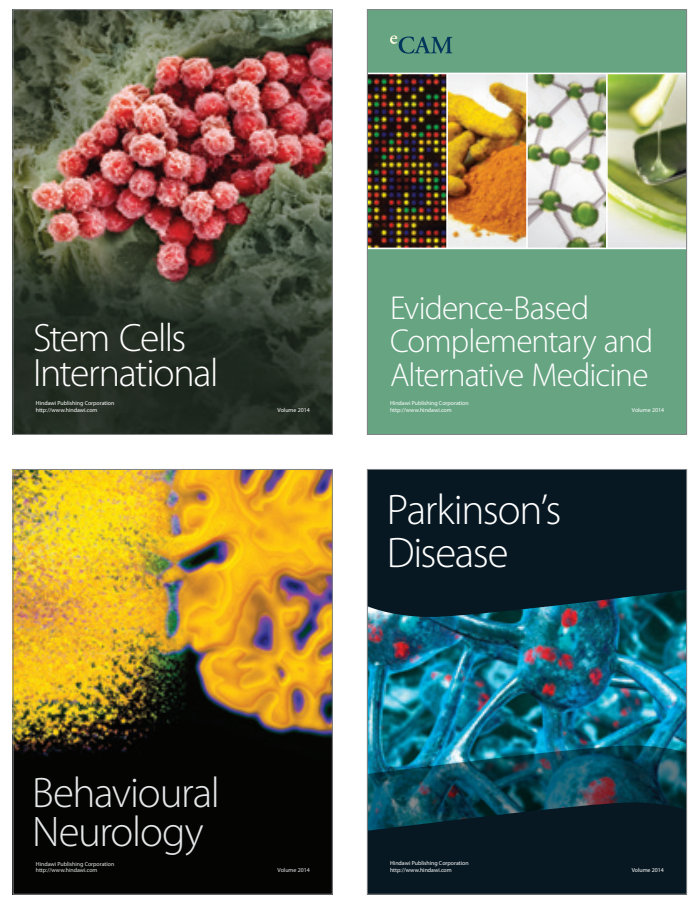
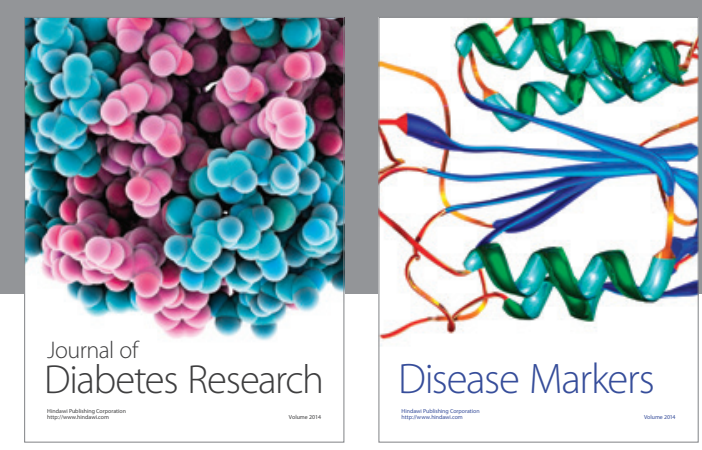

Disease Markers
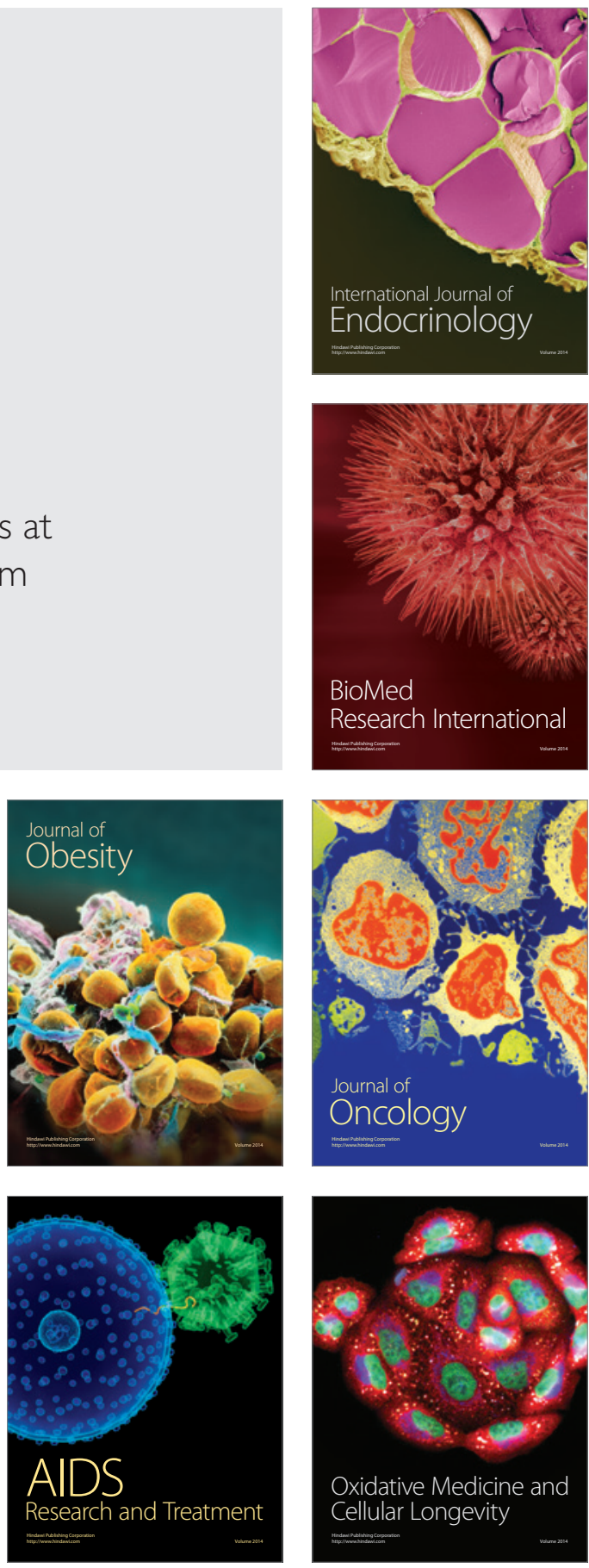